\title{
An update on the ophthalmic features in hereditary haemorrhagic telangiectasia (Rendu-Osler-Weber syndrome)
}

\author{
Solmaz Abdolrahimzadeh (D) - Martina Formisano • Carla Marani • \\ Siavash Rahimi
}

Received: 29 July 2021 / Accepted: 18 December 2021 / Published online: 16 January 2022

(C) The Author(s) 2022

\begin{abstract}
Hereditary haemorrhagic telangiectasia (HHT) or Osler-Rendu-Weber syndrome is a rare autosomal dominant disease, characterised by systemic angiodysplasia. Dysfunction of the signalling pathway of $\beta$ transforming growth factor is the main cause of HHT principally owing to mutations of the genes encoding for endoglin (ENG) and activin A receptor type II-like 1 (ACVRL1). Clinical manifestations can range from mucocutaneous telangiectasia to organ arterio-venous malformations and recurrent epistaxis. The early clinical manifestations may
\end{abstract}

S. Abdolrahimzadeh $(\bowtie)$

Ophthalmology Unit, Neurosciences, Mental Health and Sense Organs (NESMOS) Department, University of

Rome Sapienza, Rome, Italy

e-mail: solmaz.abdolrahimzadeh@uniroma1.it

S. Abdolrahimzadeh

Faculty of Medicine and Psychology, St. Andrea Hospital, Via di Grottarossa 1035/1039, 00189 Rome, Italy

M. Formisano

Department of Sense Organs, Ophthalmology Unit, University of Rome Sapienza, Azienda Policlinico Umberto I, viale del Policlinico 155, 00161 Rome, Italy

C. Marani

San Carlo Hospital, Via Aurelia 275, 00165 Rome, Italy

S. Rahimi

Istituto Dermopatico dell'Immacolata (IDI-IRCCS)

Department of Histopathology, Via Monti di Creta 104, 00167 Rome, Italy

e-mail: rahimi.siavash@gmail.com sometimes be subtle, and diagnosis may be delayed. The main ophthalmic manifestations historically reported in HHT are haemorrhagic epiphora, and conjunctival telangiectasia present in $45-65 \%$ of cases, however, imaging with wide-field fluorescein angiography has recently shown peripheral retinal telangiectasia in $83 \%$ of patients. Optimal management of HHT requires both understanding of the clinical presentations and detection of early signs of disease. Advances in imaging methods in ophthalmology such as wide-field fluorescein angiography, spectral domain optical coherence tomography, and near infrared reflectance promise further insight into the ophthalmic signs of HHT towards improved diagnosis and early management of possible severe complications.

Keywords Hereditary haemorrhagic telangiectasia . Ophthalmic · Rendu-Osler-Weber syndrome · Widefield fluorescein angiography · Multimodal imaging · Near infrared reflectance $\cdot$ Spectral domain optical coherence tomography

\section{Introduction}

Hereditary haemorrhagic telangiectasia (HHT) or Rendu-Osler-Weber syndrome is a rare systemic fibrovascular dysplasia with an incidence in the general population of 1-2/5000-8000 [1]. The disease 
affects the elastic and muscle layers of the vessel walls with a consequent increased susceptibility to ruptures and bleeding episodes [2]. HHT is characterised by multiple arterio-venous malformations (AVMs) where arteries and veins are connected in the absence of capillaries. Small AVMs are called telangiectasia, and large forms can be greater than a few millimetres up to several centimetres in diameter [3]. Transmission is autosomal dominant with incomplete expression in some cases, and sporadic mutations are involved in $20 \%$ of cases [4]. Mutations of endoglin (ENG) and activin A receptor type II-like 1 (ACVRL1) account for about $85 \%$ of cases in HHT type I and II, respectively. A third locus has been reported for HHT type III, and HHT type IV involves mutations of the SMAD4 gene that can manifest in the rare form of juvenile polyposis and (JHHT) [5-7]. Manifestations range from multiple mucocutaneous telangiectasia involving the lips, oral cavity (tongue, palate), nasopharynx, conjunctiva, ears, skin, fingers (fingertips, nail folds), arms, and trunk to AVMs in major organs such as the lung, brain, gastrointestinal tract, liver, and spinal cord [8]. (Fig. 1) Quality of life is compromised by recurrent bleeding, and morbidity is due to haemorrhage, stroke, aneurysms, and cerebral abscesses [9-11]. Initial diagnosis is frequently made based on recurrent epistaxis, oral lesions discovered during routine dental examination, and ocular signs $[12,13]$. Ophthalmic manifestations have historically been described in 45-65\% of patients with conjunctiva telangiectasia and haemorrhagic epihora, but recently advanced imaging modalities have shown peripheral retinal telangiectasia in $83 \%$ of cases [14-17].

HHT shows age-related penetrance and clinical manifestations develop over time. Careful multidisciplinary examination may reveal telangiectasia early in life. Awareness of HHT and early diagnosis is crucial to avoid the pitfalls of potentially severe complications in routine medical practice. The present review is focused on the ophthalmic manifestations of HHT in view of novel imaging methods.

\section{History}

Recurrent epistaxis, telangiectasia on the torso and the face, and lesions on the soft palate and lips were first identified by the French physician Henri Jules Louise Marie Rendu (24 July, 1844 -16 April, 1902) in 1896

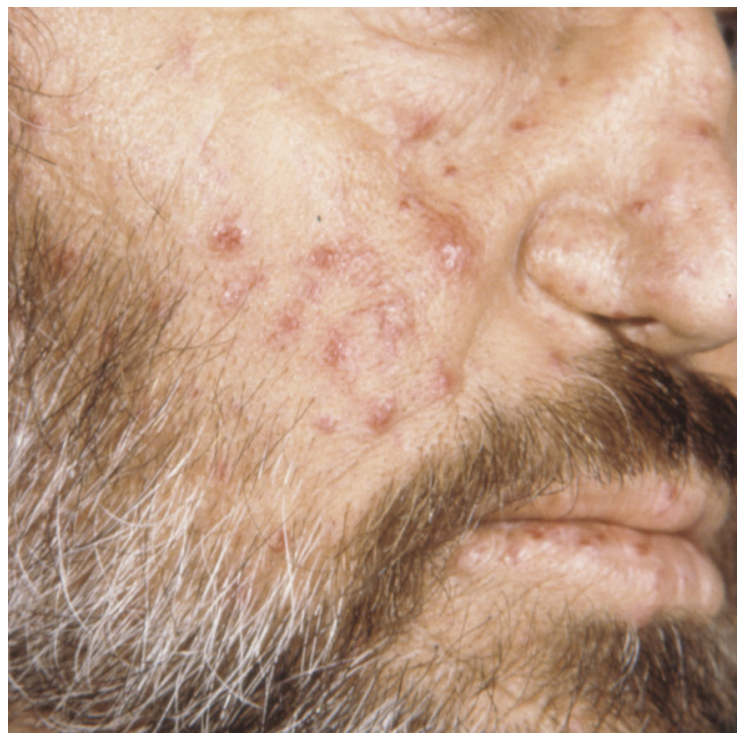

Fig. 1 Telangiectasia of the facial skin and lips in a patient with hereditary haemorrhagic telangiectasia. Reproduced with permission from: Recupero SM, Abdolrahimzadeh S, Lepore G, et al. L'apparato oculare nelle sindromi neurocutanee. Rome: Verduci Editore 2004 [63]

[18]. Sir William Osler (July 12, 1846-December 29, 1919) a Canadian physician and bibliophile, described disease inheritance, punctiform angiomata on facial skin and mucosa of the lips, cheeks, tongue, and nose with recurring epistaxis and visceral involvement of the stomach in 1901 [19]. Frederick Parkes Weber (8 May, 1863-2 June, 1962), an English dermatologist, reported a case series demonstrating the association between bleeding, mucocutaneous lesions, AVMs, and conjunctiva telangiectasia in 1907 [20]. Retinal angiomata and retinal bleeding were described in "Osler's disease" by Francois and Landau [21, 22].

\section{Epidemiology}

There is wide geographic variability however, the highest prevalence is among the Afro-Caribbean population of the island of Curaçao and Bonaire (1 case in 1331 inhabitants) from which derive the Curacao diagnostic criteria [23, 24]. HHT type 1 is more frequent in North America and in Northern Europe. HHT type 2 more prevalent in Mediterranean countries such as Italy, France, and Spain [25-30]. 


\section{Pathogenesis}

Rare diseases are currently studied and classified using molecular genetics, and HHT is not an exception to this trend. Our understanding of the pathogenesis of rare diseases such as HHT is constantly increasing with molecular diagnostic methods that enable correct and precise classification, nevertheless, the knowledge of the clinical features of HHT is essential for the practising clinician.

The genes implicated in the disease are critical for blood vessel development and response to TGF- $\beta$ signalling [3]. Mutations causing HHT type I and II are commonly of Endoglin (ENG) on chromosome 9q3334, and Activin A Receptor Like Type 1 (ACVRL-1) receptor on chromosome $12 \mathrm{q} 13$, respectively. Both genes code a membrane glycoprotein that is expressed in endothelial tissue cells and make up the surface receptor for TGF- $\beta$ that mediates vascular remodelling by affecting extracellular matrix production. ENG, ACVRL - 1 , and TGF- $\beta$ function are essential for angiogenesis [6]. SMAD4 gene mutation is not included in the currently used diagnostic criteria for HHT but is tested in cases of strong clinical suspicion of HHT that do not fulfil diagnostic criteria, and when testing family members of HHT patients [31]. This mutation is linked to a rare syndrome of combined juvenile polyposis and hereditary haemorrhagic telangiectasia JHHT [1]. A new locus for HHT (HHT type III) has been mapped to chromosome 5 and a fourth locus to chromosome 7 [7, 32].

Gòmez-Acebo et al. evaluated 206 Spanish patients with HHT and found that patients with ocular involvement had a more frequent mutation for the ENG gene rather than the ACVRL1/ALK1 gene. In contrast, Letteboer et al. reported conjunctival involvement in $13.4 \%$ of patients with HHTI and $14.6 \%$ in patients with HHTII [33].

\section{Clinical manifestations}

The vascular alterations of HHT are present in numerous organ systems of the body and are characterised by multiple capillary and venule dilatations that are fragile and can haemorrhage owing to thin vessel walls. The otorhinolaryngology specialist is often the first clinician called to make a diagnosis of HHT as recurrent epistaxis has been described as the main and first manifestation, present in $90 \%$ of patients as early as 10 years of age [2]. Mucocutaneous telengiectasia occur in about $90 \%$ of cases of HHT [34]. Histologically, they appear as a superficial set of dilated blood vessels lacking perivascular elastic fibres and smooth muscle [35]. Multiple telangiectasia may be pin-point sized or larger and spiderlike in elderly patients. Spider telangiectasia are often found in the mucous membranes of the nose, oral cavity, skin of the face and neck and increase with age [36]. Buckmiller et al. [37] reported that AVM lesions may appear with an overlying vascular blush hue in the skin akin to an early naevus flammeus [38]. When the mucosa is involved, it is usually thickened and vascular. The more advanced lesions may present enlarged vessels in the skin and underneath and noncompressible, thickened tissue with pulsation. AVMs can progress with consequent ulcerations and bleeding [37]. HHT may present with haemorrhagic vesicles, nodules, papules, or ulcers of varying size involving the gingiva, [35] the oral mucosa in the region of the tongue, hard palate, and vermilion of the lip [13]. (Fig. 2) Patients may experience intense bleeding from tooth brushing due to poor oral health and gingival disease [39]. Pathological life-threatening oral bleeds are rare but the most common are related to AVMs of the jaws or facial trauma in haemophiliac patients [40].

Formal diagnosis of HHT is made according to the Curaçao criteria: telangiectasia on the face, hand and oral cavity, recurrent epistaxis, arterio-venous malformations with visceral involvement, and familial history [23, 24]. Diagnosis is suspected when two criteria are met, whereas it is considered definite with at least three of four criteria. Following confirmed diagnosis of HHT complementary imaging tests such as computed tomography, ultrasound, and magnetic resonance imaging are advised to detect eventual involvement of organs [41-43]. Table 1 is a summary of the findings and symptoms in organ involvement. However, approximately $20 \%$ of patients are not aware of family history of disease, and only have mild symptoms [44]. Li et al. and Pierucci et al. reported an average diagnostic delay of 26 years [45-47]. The reasons behind this delay are most probably due to the rare presentation of HHT, because symptoms are variable and age dependent, and their onset is usually in the fourth $(90 \%)$ or sixth decade $(97 \%)$ of life [1]. 


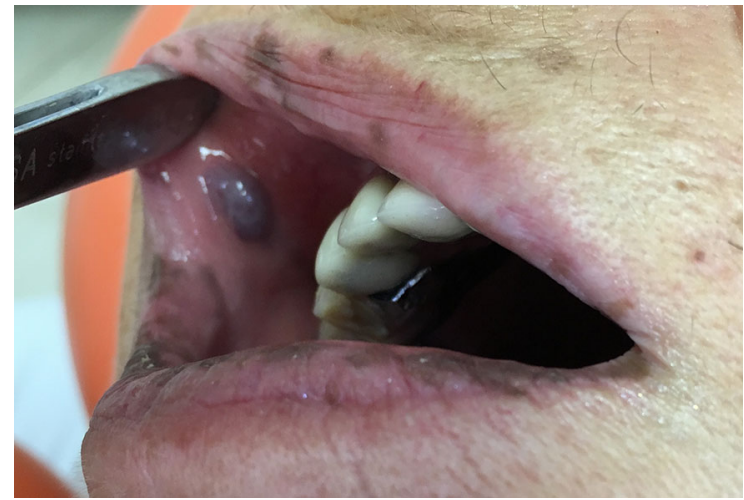

Fig. 2 Oral manifestations of hereditary haemorrhagic telangiectasia. (Courtesy of Dr. Gianmarco Bellardini)

Increased knowledge of the disease and a multidisciplinary approach can potentially accelerate diagnosis and consequently improve the quality of life of patients. Furthermore, early diagnosis is important as organ involvement, later in life, can be sudden, acute, severe, and life-threatening.

Ophthalmic manifestations

Ocular manifestations have historically been described in 35 to $65 \%$ of patients with HHT [14-17]. There have been some reports of ocular symptoms leading to the primary diagnosis of HHT through ophthalmologic examination [44, 45]. Recent advances in ophthalmology and the advent of multimodal imaging have improved evaluation of ophthalmic signs as retinal telangiectasias were recently reported in $83 \%$ of patients with HHT [48].

\section{Conjunctiva}

The frightening occurrence of bloody tears can cause considerable alarm in patients who have not yet been diagnosed. Careful slit lamp examination can reveal the cause as conjunctival telangiectasia and lead to comprehensive multidisciplinary evaluation of patients (Fig. 3). Haemorrhagic epiphora and conjunctival telangiectasia have a prevalence of $35-42 \%$. [14-16].

Geisthoff et al. found conjunctival telangiectases in 28 of 74 patients (38\%) (47 of 148 eyes). The mean age of patients was 60 years. These authors calculated the precise number of conjunctival telangiectasia and found a maximum number of 15 in each eye with a median of 2 . They did not find any correlation between age and number of conjunctival telangiectasia [15]. Gomez-Acebo et al. studied the palpebral and conjunctival location of telangiectasia. They reported upper and lower, upper, and lower eyelid localization in 30, 42, and 32 eyes, respectively. Congiuntival location was prevalently in the tarsal area in 150 eyes; and bulbar, of the border, and caruncle in 2,7 , and 1 eye, respectively [49]. Thus, the frequency of conjunctival telangiectasia can be underestimated unless

Table 1 Organ involvement in hereditary haemorrhagic telangiectasia. (AVM: arterio-venous malformations)

\begin{tabular}{|c|c|c|c|}
\hline Organ & Findings & Symptoms & References \\
\hline Brain & Cerebral AVM (5-15\%) & $\begin{array}{l}\text { headache, migraine, brain abscess, seizures, paraparesis, ischaemia, } \\
\text { stroke, transient ischaemic attacks, intracerebral and } \\
\text { subarachnoid haemorrhage }\end{array}$ & $\begin{array}{l}\text { Sabba [7] } \\
\text { Letteboer [26] } \\
\text { Shovlin [42] } \\
\text { Sadick [34] }\end{array}$ \\
\hline & Spinal AVM & subarachnoid haemorrhage, seizures, paraparesis & Begbie [43] \\
\hline Lungs & Pulmonary AVMs (15-30\%) & $\begin{array}{l}\text { right-to-left shunt with possible secondary chronic hypoxemia and } \\
\text { paradoxical embolism }\end{array}$ & $\begin{array}{l}\text { Sadick [34] } \\
\text { Guttmacher } \\
\text { [11] }\end{array}$ \\
\hline $\begin{array}{l}\text { Digestive } \\
\text { system }\end{array}$ & $\begin{array}{l}\text { Gastrointestinal AVM } \\
\text { (Gastrointestinal bleeding } \\
20-40 \%)\end{array}$ & $\begin{array}{l}\text { gastrointestinal bleeding with possible iron deficiency anaemia or } \\
\text { acute gastrointestinal haemorrhage }\end{array}$ & Begbie [44] \\
\hline Liver & $\begin{array}{l}\text { Liver AVM (Liver } \\
\text { telangiectasia } 8-31 \% \text { ) }\end{array}$ & $\begin{array}{l}\text { portal hypertension, high output heart failure, biliary disease, shunt } \\
\text { between hepatic arteria and portal vein and consequent } \\
\text { pseudocirrhosis }\end{array}$ & Daina [41] \\
\hline
\end{tabular}


thorough congiuntival examination is carried out with eyelid eversion.

Differential diagnosis of HHT related bleeding includes haematological disorders such as haemophilia, conjunctivitis, hysterical psychosis, vascular tumours, granulomas, post-surgical ocular conditions or manipulation, naslolacrimal duct pathologies with regurgitant flow to the conjunctiva, and extreme physical exertion [50]. Of interest is the report by Knox who reported a patient with injection of the medial bulbar conjunctiva, where initial diagnosis was episclerits [44]. The authors described an absence of response to topical prednisolone and because the vessels were mobile over the underlying episclera, more detailed history and examination led to diagnosis of conjunctival telangiectasia and HHT.

Contrasting results were reported for correlations between conjunctival and visceral manifestaions of HHT. Geisthoff et al. used the Curaçao criteria to evaluate possible correlations but found that the percentage of patients with visceral involvement was similar for patients with conjunctival telangiectasia (39\%) and those without (41\%) [15]. On the other hand, Gòmez-Acebo et al. found that conjunctival telangiectasia in HHT were associated with lung involvement and suggested that conjunctival telangiectasias could be a non-invasive marker of HHT manifestations of the lung. These authors also found that oral haemorraghes and grade of telangiectasia of the nose and intensity of epistaxis are also associated with conjunctival telangiectasia [49].

There are no reports of specific treatment modalities for conjunctival telangiectasia, or conjunctival post-haemorrhagic granulomatous lesions as haemorrhage is usually not severe [8]. The rare case reports of cautery for recurrent haemorrhages were reported by Garner et al. and Pandolfi et al. in 1956, and 1978, respectively [51, 52]. Brant et al. in 1989 also reported one case of conjunctival telangiectasia on the upper eyelid that necessitated thermal cautery because of multiple episodes of bleeding [14].

Although bleeding owing to conjunctival telangiectasia is not severe, once HHT is confirmed by molecular diagnosis, patients with history of gastrointestinal bleeding, frequent epistaxis, or possibly frequent conjunctival haemorrhages should be instructed to avoid anticoagulants such as warfarin or nonsteroidal antiinflammatory agents that have an effect on platelet functionality such as ibuprofen and asprin

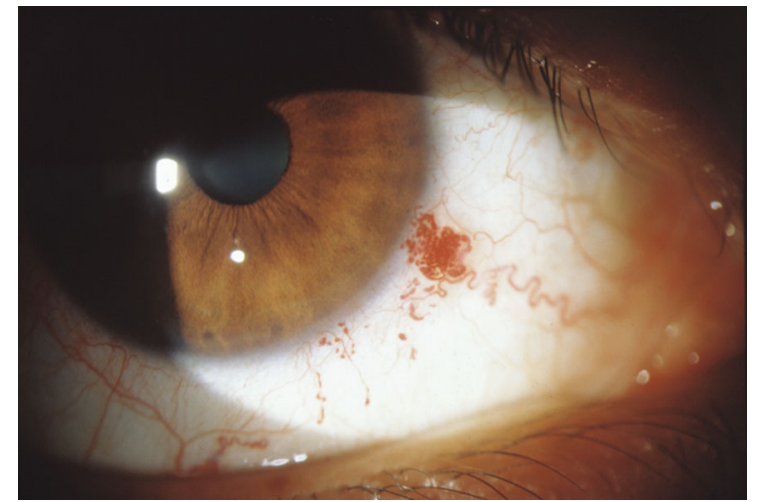

Fig. 3 Conjunctival telangiectasia in a patient with hereditary haemorrhagic telangiectasia. Reproduced with permission from: Recupero SM, Abdolrahimzadeh S, Lepore G, et al. L'apparato oculare nelle sindromi neurocutanee. Rome: Verduci Editore 2004:71 [63]

unless required for other medical conditions considering the risks and benefits of such therapy.

\section{Retina}

Retinal vascular malformations such as arterio-venous fistula, angiectasia, phlebectasia, and angioma have been described with a variable percentage from 0 to $10 \%[14,16,53]$. However, retinal telangiectasia is reported with different frequencies based on the modality of examination of patients. Geisthoff et al. reported retinal telangiectasia in 1 of 75 patients examined [15]. These authors concluded that the prevalence of retinal telangiectases $(<1.3 \%)$ did not justify ophthalmological screening procedures. Similarly, Gòmez-Acebo et al. found a $1.12 \%$ prevalence of retinal involvement but acknowledged that subtle vascular retinal abnormalities may have been overlooked as patients only underwent ophthalmoscopic examination [49]. Retinal imaging has given new insight on retinal telangiectasia. Fluorescein angiography (FFA) is a method used for the evaluation of retinal circulation by administering an intravenous bolus of fluorescein sodium salt and taking serial photographs of the vascular network of the retina. Brant et al. carried out FFA in 2 of 20 patients (10\%) with retinal telangiectasia; one patient had telangiectasia adjacent to the optic disc in one eye and in the papillomacular bundle in the fellow eye without leakage in any frame of angiography. A second patient showed fine telangiectasia throughout the retina [14]. 
Mennel et al. also performed FFA and described parafoveal telangiectasia in both eyes of one patient and a choroidal neovascular membrane with leakage in another patient. This patient was successfully treated in 2005 with photodynamic therapy (prior to the widespread first choice use of anti-VEGF therapy in ophthalmology for neovascular membranes); leakage and exudation resolved and visual acuity remained stable with follow up at one year. The authors, however, acknowledged that the idiopathic parafoveal telangiectasia could have been a coincidental finding or in the spectrum of HHT and speculated the possible influence of endoglin in the pathogenesis [54]. The incidence of retinal alterations has changed through recent studies by Sindhar et al. who examined eighteen patients with HHT through wide-field FFA. The authors found $83 \%$ of patients with peripheral telangiectasis with capillary dilatation and tortuosity in the nasal and temporal retina but no vascular or structural alterations within the macula. They suggested that retinal vascular malformations might be easily overlooked with fundus examination or fundus photography [48].

As FFA involves the use of dye and is a relatively invasive method, this technique may not be feasible in all cases. Near infrared imaging uses a light source with a wavelength of approximately $850 \mathrm{~nm}$ and for screening purposes wide-field NIR imaging may be a more practical method of screening. NIR imaging is now widely accessible in ophthalmology and has been recently used to observe microvascular retinal vascular abnormalities, as a further biomarker, in neurofibromatosis type 1 that are difficult to detect on ophthalmoscopic examination [55, 56]. Although Rinaldi et al. used NIR imaging in HHT [8] they did not comment on any vascular alterations, probably because the instrument provides images limited to the posterior pole, whereas telangiectasia are commonly located in the peripheral retina. NIR imaging with a wide-field modality could be promising as a screening tool as it is a rapid and non-invasive imaging method available in all major hospital facilities.

Retinal pigmentary alterations overlying choroidal ectatic vessels were reported by Tsai et al. The authors suggested that the altered choroidal vessels cause alterations of the retinal pigment epithelium (RPE) possibly owing to micro-exudation from ectactic vessels [54, 57]. Rinaldi et al. used infrared and red free images and found RPE alterations in three of 8 patients. In particular, they found atrophy temporal to the macula between the superior and inferior vascular arcades in areas corresponding to retinal telangiectasia in one patient; atrophy of the RPE-coriocapillaris complex of the posterior pole excluding the macula in both eyes of a second patient; and subtle changes of the peripheral RPE and defined areas of choriocapillaris and RPE atrophy extending from the posterior pole to the mid-periphery in correspondence of the vascular bed in a third patient [8].

Spectral domain optical coherence tomography (SD-OCT) is a non-invasive, dye free technique that uses a light source with a wavelength of approximately $850 \mathrm{~nm}$, with maximum resolution sensitivity to obtain visualisation of the retinal layers and the choroid. Rinaldi et al. reported SD-OCT features of RPE hypo-reflectivity, with visible choroidal vessels, large choroidal vessels, and choroid hyper-reflectivity features in 3 of 8 patients [8].

A further development in ophthalmological imaging is optical coherence tomography angiography (OCT-A). This is a non-invasive high resolution imaging technique that enables to visualise the retinal and coroideal circulation. This method enables quantitative and qualitative evaluation of the superficial and deep retinal vascular plexuses, the choriocapillaris vessel density, and the foveal avascolar zone. Sindhar et al. performed OCT-A analysis evaluating the mean foveal avascular zone and foveal/parafoveal vessel density, however, they did not find vascular or architectural changes in the macular area. This is probably because HHT manifests with peripheral telangiectasia, and the posterior pole is not involved [48].

Retinal telangiectasia in patients with HHT are stable, and seldom cause symptoms, therefore, prophylaxis or treatment is not required. However, these are additional signs that can help in the early detection of signs of HHT.

\section{Choroid}

As the choroideal circulation is difficult to observe when the pigmented epithelium is intact, indocyanine green angiography (ICG-A), carried out with a watersoluble dye with high protein binding capacity that does not pass through the fenestrations of the choriocapillaris, enables choroidal circulation visualisation owing to the ability of infrared radiation emitted by the 
indocyanine to penetrate through normal ocular pigments. Tsai et al. performed ICG-A in one patient and found dilatation and tortuosity of choroidal vessels [57]. They found ectatic choroidal vessels that showed intense hyperfluorescence with adjacent hypofluorescence in the early frames extending from the peripapillary zone to the peripheral retina. They did not report leakage of dye in any frame and suggested that the altered vessels have an intact barrier. Rinaldi et al. reported ICG-A features consisting of large choroidal vessels, diffuse moderate leakage, choriocapillaris atrophy in the mid-periphery, and isolated choroidal telangiectasia in 3 of eight patients [8].

The genes implicated in HHT are critical for blood vessel development and response to TGF- $\beta$ signalling [3]. Owing to choriocapillaris atrophy findings together with RPE alterations in HHT patients, Rinaldi et al. speculated that RPE atrophy causes choriocapillaris loss and photoreceptor degeneration or alternatively choroidal vascular insufficiency results in dysfunction of the RPE and photoreceptor degeneration [8]. This is supported by the findings of Schlingemann who reported that TGF- $\beta$ is also a neurotrophic factor involved in maintaining the physiological function of the RPE and its connections with the retinal cells and the choriocapillaris, giving trophic support and contributing to the angiogenic balance [58].

Treatment is not indicated for choroidal vascular anomalies; however, choroidal haemorrhages have been reported during phacoemusification for cataract surgery and during vitrectomy for retinal detachment $[53,59]$. Thus, during ocular operations the risk of choroidal haemorrhage seems to be elevated, and recognition of this severe complication is fundamental in order to take appropriate precautions in planning surgery.

\section{Rare ophthalmic manifestations}

Rare reports are by Kuchtey et al., who described a case of open angle glaucoma in a patient and his sister with type II HHT [60]. The authors suggested that this finding could be related to the disease, as it is caused by mutations in genes involved in the TGF- $\beta$ superfamily signalling, which also plays a role in glaucoma pathogenesis. Van Went et al. described a case of spontaneous thrombosis of an orbital AVM leading to proptosis, chemosis, and ocular hypertension as the presenting symptom in one patient [61]. In one case, longstanding hypoxemia and polycythemia due to a large pulmonary AVM with right-to-left shunt, contributed to hyperviscosity and consequent branch retinal artery occlusion in a patient with HHT [62].

\section{Conclusions}

HHT is a rare disease with a low but existing rate of life-threatening complications. The disease is frequently under-diagnosed as it typically relies on clinical manifestations. Ophthalmic signs are not included in the diagnostic criteria but their detection can lead to early diagnosis of HHT. The ophthalmologist can aid in detecting telangiectasia of the conjunctiva or the retina owing to the wide availability of advanced imaging methods. NIR may be a promising imaging modality to detect peripheral telangiectasia as retinal or choroidal biomarkers of HHT. Molecular diagnostics can successively be used to confirm diagnosis enabling to inform families of the possibility of further screening and early treatment.

Acknowledgements The authors are grateful to Dr. Gianmarco Bellardini for providing the figure for the oral manifestations of hereditary haemorrhagic telangiectasia.

Funding No funding was received.

Availability of data and material Not applicable.

\section{Declarations}

Conflict of interest The authors do not report conflicts of interest.

Consent for publication Consent for publication was obtained for the figures.

Open Access This article is licensed under a Creative Commons Attribution 4.0 International License, which permits use, sharing, adaptation, distribution and reproduction in any medium or format, as long as you give appropriate credit to the original author(s) and the source, provide a link to the Creative Commons licence, and indicate if changes were made. The images or other third party material in this article are included in the article's Creative Commons licence, unless indicated otherwise in a credit line to the material. If material is not included in the article's Creative Commons licence and your intended use is not permitted by statutory regulation or exceeds the permitted use, you will need to obtain permission directly from the copyright holder. To view a copy of this licence, visit http://creativecommons.org/licenses/by/4.0/. 


\section{References}

1. Gallione CJ, Repetto GM, Legius E et al (2004) A combined syndrome of juvenile polyposis and hereditary haemorrhagic telangiectasia associated with mutations in MADH4 (SMAD4). Lancet 363:852-859

2. Rapoport PG, Uvo IP, Costa KS et al (2003) Síndrome de rendu-osler-weber: tratamento clínico e cirúrgico. Rev Bras Otorrinolaringol 694:577-580

3. McDonald J, Pyeritz RE (2017) Hereditary hemorrhagic telangiectasia gene reviews ${ }^{\circledR}$. University of Washington, Seattle, WA

4. Haitjema T, Westermann CJJ, Overtoom TTC et al (1996) Hereditary hemorrhagic telangiectasia (Osler- WeberRendu syndrome)-new insights in pathogenesis, complications, and treatment. Arch Intern Med 156:714-719

5. Letteboer TGW, Mager JJ, Snijder, et al. (2006) Genotypephenotype relationship in hereditary hemorrhagic telangiectasia. J Med Genet, 43: 371-377.

6. Dakeishi M, Shioya T, Wada Y et al (2002) Genetic epidemiology of hereditary hemorrhagic telangiectasia in a local community in the northern part of Japan. Hum Mutat 19:140-148

7. Sabba C (2005) A rare and misdiagnosed bleeding disorder: hereditary hemorrhagic telangiectasia. J Thromb Haemost 3:2201-2210

8. Rinaldi M, Buscarini E, Danesino C et al (2011) Ocular manifestations in hereditary hemorrhagic telangiectasia (Rendu-Osler-Weber disease): a case-series. Ophthalmic Genet 32:12-17

9. Shovlin CL (2010) Hereditary haemorrhagic telangiectasia: pathophysiology, diagnosis and treatment. Blood Rev 24:203-219

10. Sabba C, Pasculli G, Suppressa P et al (2006) Life expectancy in patients with hereditary haemorrhagic telangiectasia. QJM Mon J Assoc Phys 99:327-334

11. Grosse SD, Boulet SL, Grant AM et al (2014) The use of US health insurance data for surveillance of rare disorders: hereditary hemorrhagic telangiectasia. Genet Med 16:33-39

12. Guttmacher AE, Marchuk DA, White RL (1995) Hereditary haemorragic telangiectasia. New England J Med 333:918-924

13. Da Silva Santos PS, Fernandes KŚ, Magalhães MH (2009) Osler-Weber-Rendu syndrome-dental implications. J Can Dent Assoc (Tor) 75:527-530

14. Brant AM, Schachat AP, White RI (1989) Ocular manifestations in hereditary haemorragic telangiectasia (RenduOsler-Weber disease). Am J Ophthalmol 107:642-646

15. Geisthoff UW, Hille K, Ruprecht KW et al (2007) Prevalence of ocular manifestations in hereditary hemorrhagic telangiectasia. Graefes Arch Clin Exp Ophthalmol 245:1141-1144

16. Vase I, Vase P (1979) Ocular lesions in hereditary haemorrhagic telangiectasia. Acta Ophthalmol (Copenh) 57:1084-1090

17. Pizzamiglio-Martin C, Gil-Cazorla R, Guzman-Blazquez J (2008) Ophthalmologic diagnosis of hereditary hemorrhagic telangiectasia or Rendu-Osler-Weber disease. Arch Soc ESP Ophtalmol 83:381-384
18. Rendu HJ. Épistaxis répétées chez un sujet porteur de petits angiomes cutanés et muqueux. Gaz Hop 1896:1322-1323.

19. Osler W (1901) On a family form of recurring epistaxis, associated with multiple telangiectases of the skin and mucous membranes. Bull Johns Hopkins Hosp 7:333-337

20. Weber FP (1907) Multiple hereditary developmental angiomata (telangiectases) of the skin and mucous membranes associated with recurring haemorrhages. Lancet $2: 160-162$

21. Francois J (1938) L'angiomatose hemorragique familiale et ses complications oculaires. Arch Ophthalmol 2:245

22. Landau J, Nelken E, Davis E (1956) Hereditary hæmorrhagic telangiectasia with retinal and conjunctival lesions. Lancet 271(6936):230-231

23. Westermann CJJ, Rosina AF, De Vries V, de Coteau PA (2003) The prevalence and manifestations of hereditary hemorrhagic telangiectasia in the Afro- Caribbean population of the Netherlands antilles: a family screening. Am J Med Genet A 116A:324-328

24. Te Veldhuis EC, te Veldhuis AH, van Dijk FS et al (2008) Rendu-Osler-Weber disease: update of medical and dental considerations. Oral Surg, Oral Med Oral Pathol Oral Radiol Endodontol 105:38-41

25. Abdalla SA, Geisthoff UW, Bonneau D et al (2003) Visceral manifestations in hereditary haemorrhagic telangiectasia type 2. J Med Genet 40:494-502

26. Letteboer TG, Zewald RA, Kamping EJ et al (2005) Hereditary hemorrhagic telangiectasia: ENG and ALK-1 mutations in Dutch patients. Hum Genet 116:8-16

27. Lastella $P$, Sabbà C, Lenato GM et al (2003) Endoglin gene mutations and polymorphisms in Italian patients with hereditary haemorrhagic telangiectasia. Clin Genet 63:536-540

28. Olivieri C, Mira E, Delù G et al (2002) Identification of 13 new mutations in the ACVRL1 gene in a group of 52 unselected Italian patients affected by hereditary haemorrhagic telangiectasia. J Med Genet 39:E39

29. Lesca G, Plauchu H, Coulet F et al (2004) Molecular screening of ALK1/ACVRL1 and ENG genes in hereditary hemorrhagic telangiectasia in France. Hum Mutat 23:289-299

30. Fernandez-L A, Sanz-Rodriguez F, Zarrabeitia R et al (2006) Mutation study of Spanish patients with hereditary hemorrhagic telangiectasia and expression analysis of Endoglin and ALK1. Hum Mutat 27:295

31. Karlsson T, Cherif $H$ (2018) Mutations in the ENG, ACVRL1, and SMAD4 genes and clinical manifestations of hereditary haemorrhagic telangiectasia: experience from the center for Osler's disease, Uppsala University Hospital. Ups J Med Sci 123:153-157

32. Bayrak-Toydemir P, McDonald J, Akarsu N, Toydemir RM, Calderon F, Tuncali $\mathrm{T}$ et al (2006) A fourth locus for hereditary hemorrhagic telangiectasia maps to chromosome 7. Am J Med Genet A 140:2155-2162

33. Letteboer TGW, Mager H-J, Snijder RJ et al (2008) Genotype-phenotype relationship for localization and age distribution of telangiectases in hereditary hemorrhagic telangiectasia. Am J Med Genet A 146A(21):2733-2739

34. Sadick H, Sadick M, Gotte K, Naim R, Riedel F, Bran G et al (2006) Hereditary hemorrhagic telangiectasia: an 
update on clinical manifestations and diagnostic measures. Wien Klin Wochenschr 118:72-80

35. Bartolucci EG, Swan RH, Hurt WC (1982) Oral manifestations of hereditary hemorrhagic telangiectasia (osler-weber-rendu disease) review and case reports. J Periodontol 53:163-167

36. Scopp IW, Quart A (1958) Hereditary hemorrhagic telangiectasia involving the oral cavity. Oral Surg, Oral Med, Oral Pathol 4220(58):90296-90302

37. Buckmiller LM, Richter GT, Suen JY (2010) Diagnosis and management of hemangiomas and vascular malformations of the head and neck. Oral Dis 16:405-418

38. Abdolrahimzadeh S, Scavella V, Battaglia D, Recupero SM (2016) Spectral domain optical coherence tomography of choroidal and outer retinal layer thickness in the sturge weber syndrome. Curr Eye Res 41:1614-1617

39. Hopp RN, De Siqueira DC, Sena-Filho M, Jorge J (2013) Oral vascular malformation in a patient with hereditary hemorrhagic telangiectasia: a case report. Spec Care Dent 33:150-153

40. Ahamed SK, Al-Thobaiti Y (2015) Life-threatening oral bleed-a rare presentation of hereditary hemorrhagic telangiectasia. J Oral Maxillofac Surg 73:1465.e1-1465.e5

41. Daina E, D’Ovidio F, Sabbà C (2006) Introduction: hereditary hemorrhagic telangiectasia as a rare disease. Curr Pharm Des 12:1171-1172

42. Shovlin CL, Letarte M (1999) Hereditary haemorrhagic telangiectasia and pulmonary arteriovenous malformations: issues in clinical management and review of pathogenic mechanisms. Thorax 54:714-729

43. Begbie ME, Wallace GMF, Shovlin CL (2003) Hereditary haemorrhagic telangiectasia (osler-weber-rendu syndrome): a view from the 21 st century. Postgrad Med J 79:18-24

44. Knox FA, Frazer DG. Ophthalmic presentation of hereditary haemorrhagic telangiectasia. Eye 2004, 16. 947-949.

45. Li S, Wang SJ, Zhao YQ. Clinical features and treatment of hereditary hemorrhagic telangiectasia. Medicine 2018. 97(31).

46. Pierucci P, Lrnato GM, Suppressa P et al (2012) A long diagnostic delay in patients with hereditary haemorrhagic telangiectasia: a questionnaire-based retrospective study. Orphanet J Rare Dis 7:33

47. Soong HK, Pollock DA (2000) Hereditary hemorrhagic telangiectasia diagnosed by the ophthalmologist. Cornea 19(6):849-850

48. Sindhar S, O'Bryhim BE, Licata J et al (2019) Identification of retinal vascular lesions using ultra-widefield angiography in hereditary hemorrhagic telangiectasia patients. Ophthalmol Retin 3:510-515

49. Gòmez-Acebo PSR, De La Mora A et al (2020) Ocular lesions in herediary hemorrhagic telangiectasia: genetics and clinical characteristics. Orphanet J of Rare Dis 15:168
50. Duke-Elder S. Diseases of the Outer Eye, Conjunctiva. In system of ophthalmology, vol. 8, pt. $1^{\text {St }}$.Louuis, C.V.Mosby, 1965, pp37-39.

51. Garner LL, Grossman EE (1956) Hereditary hemorrhagic telangiectasis with beta irradiation of a conjunctival lesion. Am J Ophthalmol 41:672

52. Pandolfi M, Ehinger B (1978) Conjunctival bleeding in Osler's disease with associated platelet dysfunction A case report. Acta Ophthalmol 56:75

53. Mahmoud TH, Deramo VA, Kim T, Fekrat S (2002) Intraoperative choroidal hemorrhage in the Osler- Rendu-Weber syndrome. Am J Ophthalmol 133:282-284

54. Mennel S, Hoerle S, Meyer CH (2006) Photodynamic therapy in symptomatic parafoveal telangiectasia secondary to Osler-Rendu-Weber disease. Acta Ophthalmol Scand 84:273-275

55. Abdolrahimzadeh S, Plateroti AM, Recupero SM, Lambiase A. An update on the ophthalmologic features in the phakomatoses. J Ophthalmol 2016. Article ID 3043026,

56. Abdolrahimzadeh S, Felli L, Piraino DC et al (2014) Retinal microvascular abnormalities overlying choroidal nodules in neurofibromatosis type 1. BMC Ophthalmol 14:146

57. Tsai DC, Wang AG, Lee AF et al (2002) Choroidal telangiectasia in a patient with hereditary hemorrhagic telangiectasia. Eye (Lond) 16:92-94

58. Schlingemann RO (2004) Role of growth factors and the wound healing response in age-related macular degeneration. Graefes Arch Clin Exp Ophthalmol 242:91-101

59. Szaflik J, Kamińska A, Zaras M. (2005) Intraoperative choroidal hemorrhage in patient with Osler-Rendu syndrome. Klin Oczna 107:133-136

60. Kuchtey RW, Naratadam GT, Kuchtey J (2015) Severe open angle glaucoma in hereditary hemorrhagic telangiectasia. Clin Case Rep 3:725-727

61. Van Went C, Ozanne A, Saliou G et al (2011) Spontaneous thrombosis of an orbital arteriovenous malformation revealing hereditary haemorrhagic telangiectasia (RenduOsler-Weber disease) a case report. Interv Neuroradiol 17:466-741

62. Hackelton KL (2006) Acute visual loss as the presenting complaint of hereditary hemorrhagic telangiectasia. J Am Board Fam Med 19:637-640

63. Recupero SM, Abdolrahimzadeh S, Lepore G et al (2004) L'apparato oculare nelle sindromi neurocutanee. Verduci Editore, Rome, pp 71-72

Publisher's Note Springer Nature remains neutral with regard to jurisdictional claims in published maps and institutional affiliations. 